\title{
Market Predictability and Non-Informational Trading
}

\author{
Terrence Hendershott \\ Mark S. Seasholes \\ U.C. Berkeley \\ HKUST
}

This Version: 11-Mar-2009*

\begin{abstract}
This paper studies the ability of non-informational order imbalances (buy minus sell volume) to predict daily stock returns at the market level. Using a model with three types of participants (an informed trader, liquidity traders, and a finite number of arbitrageurs), we derive predictions relating returns to lagged returns and lagged order imbalances. Empirical tests using New York Stock Exchange non-informational basket/portfolio trading data provide results consistent with adverse selection at the market-level, but no evidence of limited risk-bearing capacity. Finally, we establish that these market-wide non-informational order imbalances also affect individual stock return comovement by examining additions to the S\&P500 Index.
\end{abstract}

Keywords: Return Predictability, Liquidity, Comovement

JEL Number: G1, G12

${ }^{*}$ We thank Kewei Hou, Charles Jones, Albert Menkveld, Tarun Ramadorai, and seminar participants at the HKUST 2008 Symposium, 2009 University of Sydney Microstructure Conference, Tsinghua University, and Hong Kong University for helpful comments. We thank the NYSE for providing data. Contact information: Mark S. Seasholes, HKUST; Tel: 510-931-7531; email: Mark.Seasholes@emailias.edu; Terry Hendershott, Haas School of Business, 545 Student Services Bldg., Berkeley, CA 94720-1900; Tel: 510-643-0619; email: hender@haas.berkeley.edu. 


\section{Introduction}

This paper studies the ability of non-informational order imbalances to predict daily stock returns at the market or index level. Prior research at the individual stock level shows that non-informational characteristics such as index membership, listing exchange, and the location of a firm's headquarters can affect returns. When a stock's index membership or location changes, the group of investors who trade the stock may change (clientele shifts), thus order imbalances may change, which can cause changes to the underlying stock returns. Non-informational imbalances can impact returns if arbitrageurs (market makers) are concerned about the risk of holding inventory and/or adverse selection.

We extend single-stock results by showing non-informational order imbalances (buy volume minus sell volume) also affect (aggregate) market returns. If there is a common component to imbalances, many stocks simultaneously experience excess buy (sell) orders. Arbitrageurs who trade against the orders may end up with large short (long) inventory positions. The arbitrageurs may also worry that trades are generated by those who have superior information. ${ }^{1}$ A goal of this paper is to understand whether limited risk-bearing capacity or concern about adverse selection provides a better explanation for the ability of non-informational imbalances to predict market returns.

If arbitrageurs have limited risk-bearing capacity - they are risk averse and do not have infinite capital - then non-informational traders may have to buy at prices above (or sell at prices below) fundamental values. ${ }^{2}$ Arbitrageurs who provide liquidity to these traders are later compensated for their services when prices revert to fundamental values. These transitory price deviations cause two observable effects in stock returns: excess volatility and a predictable component.

Models with informed trading predict that arbitrageurs adjust prices to reflect the expected information in order imbalances - e.g., Kyle (1985). In these models, risk neutral arbitrageurs only observe total order imbalances which are a mixture of informed and non-informed

\footnotetext{
${ }^{1}$ The most obvious examples of traders with market-level information are index-arbitrage traders who sell stocks when they are expensive relative to index futures and bonds. Informed trade may also stem from investors who study market-wide components such as interest rate or economic forecast movements. Evans and Lyons (2002) show that order imbalances in the foreign exchange market contain information about daily exchange rates. Evans and Lyons $(2005,2008)$ discuss the more subtle possibility that the aggregation of individual orders provides information about future macro variables.

${ }^{2}$ Microstructure models with inventory provide predictions that the inventory of a market maker should negatively predict future stock returns. For example, see Amihud and Mendelson (1980), Ho and Stoll (1981), Grossman and Miller (1988), and Madhavan and Smidt (1993).
} 
trading. The market makers set efficient prices conditional on the total order imbalances. The unobserved non-informational order imbalances cause prices to overshoot fundamental values, while prices under react to the unobserved informed order imbalances. The market makers set prices so that these two effects cancel each other out resulting in returns and total order imbalances having zero correlation with future returns.

We test whether observed market data are consistent with the presence of limited risk-bearing capacity and/or informed trading. To conduct such tests, we write down a model with three types of traders: 1) A risk-neutral informed trader; 2) Non-informational liquidity traders; and 3) A finite number of symmetric and risk-averse arbitrageurs. We next derive expressions relating market returns to lagged returns and lagged non-informational imbalances. The model's predictions vary under different scenarios such as limited risk-bearing capacity, unlimited risk-bearing capacity, informed trading, and no informed trading.

Our baseline model with limited risk-bearing capacity and informed trading (adverse selection) predicts that returns are negatively autocorrelated and that returns are negatively correlated with lagged non-informational order imbalances. In a bivariate regression of returns on both lagged returns and lagged non-informational order imbalances, the model predicts the coefficient on lagged returns is positive while the coefficient on lagged non-informational order imbalance is negative. The coefficient on lagged returns is positive because lagged returns (conditional on non-informational trading) is correlated with the degree of informed trading.

In the case with unlimited risk-bearing capacity and informed trading, our model predicts returns have zero autocorrelation (as opposed to the negative autocorrelation in the baseline model). In the case with limited risk-bearing capacity and no informed trading, the model predicts the bivariate regression's coefficient on lagged returns is zero (as opposed to positive.)

We test the predictions of our model using seven years of non-public data from the New York Stock Exchange (NYSE). We identify the buying and selling of a group of portfolio traders. Program trading (PT) is a widely used, and natural way, for portfolio and index traders to minimize trading costs. ${ }^{3}$ The $\$ 1$ million minimum size requires program traders to express substantial trading interest to a broker, something unappealing to traders concerned about revealing information in their order. Subrahmanyam's (1991a) theoretical model shows that

\footnotetext{
${ }^{3}$ Program trading is defined by the New York Stock Exchange (NYSE) as the purchase or sale of 15 or more stocks having a total market value of $\$ 1$ million or more. Brokers offer very low commissions for program trading. While these characterizations fit index traders, investors trading other types of portfolios use PT as well. See Section 3 for further discussion. Section 5 empirically verifies that program traders lose money on average.
} 
non-informational traders separate themselves from informed traders by trading a portfolio of securities together. We define program traders' daily order imbalance in a given stock $\left(O I B_{i, t}\right)$ as the buy volume minus sell volume divided by the stock's market capitalization. We then define the market-wide daily order imbalance $\left(O I B_{t}\right)$ as the market capitalization weighted average of order imbalance across all stocks. We show that program traders are non-informational liquidity traders in that their trades lose money on average. Program trading represents $13.4 \%$ of daily NYSE trading volume on average.

Consistent with both the limited risk-bearing capacity and adverse selection effects, $O I B_{t}$ has a positive contemporaneous correlation of 0.530 with market returns. We find $O I B_{t}$ has a -0.064 correlation with the market return on day $t+1$. However, the value-weighted market return has zero autocorrelation, inconsistent with limited risk-bearing capacity being a major friction at the market level. Consistent with adverse selection, a bivariate regression of returns on both lagged returns and lagged $O I B_{t}$ gives a positive coefficient on lagged returns and a negative coefficient on lagged $O I B_{t}$. Thus, we find evidence that non-informational trading impacts market returns due to adverse selection, but do not find support of limited risk-bearing capacity at the market level.

To control for $O I B$ 's positive autocorrelation and $O I B$ 's negative correlation with lagged returns, we estimate a vector autoregression (VAR) using market-level $O I B$ and returns. The VAR results are consistent with regression results. Unexpected shocks to order imbalances are positively correlated with contemporaneous returns. Unexpected shocks to $O I B$ also negatively predict the following day's returns. An unexpected shock to returns (orthogonal to order imbalances) positively predicts the following day's returns.

Finally, we study S\&P500 Index additions in order to link our market-level examination of non-informational trading to past literature on non-informational events and individual security returns. We confirm that after a security is added to the S\&P500 Index, the stock experiences increased return comovement with other stocks already in the S\&P500 as in Vijh (1994). The stock also experiences decreased comovement with stocks not in the index as in Barberis, Shleifer, and Wurgler (2005). The standard explanation for changes in comovement is that a group of non-informational traders begins trading a stock after it joins an index.

We measure a stock's order imbalance comovement before and after it joins the S\&P500 Index. A stock's $O I B$ beta increases after the stock is added to the index (the beta comes from a regression of the stock's $O I B_{i, t}$ on the $O I B_{t}$ of other S\&P500 stocks). The result 
parallels existing findings that a stock's return beta increases after an addition. In addition, and similar to what is found with returns, there is a decrease in the added stock's OIB beta with non-S\&P500 stocks. Also consistent with indexers using program trading, when stocks are added to the S\&P500 the program traders buy a significant fraction of shares outstanding (more than 1\% of the company) and the volume of program trading in the stock also increases. Consistent with our OIB measure being linked to a common component in the returns of S\&P500 stocks, a recently added stock's cross-beta also increases - a stock's cross-beta is a measure of comovement between returns and order imbalances estimated from a regression of the stock's returns on market-wide order imbalances.

Our results are related to recent research on trading activity affecting individual security returns and having a transitory impact on stock prices. Froot and Dabora (1999) study Siamese twin stocks - two stocks with claims on the same company but that are traded on different stock exchanges. They find that these stocks comove more with stocks on the exchange they are listed on. Chan, Hameed, and Lau (2003) extend these location of trade results by studying the de-listing of some Jardine Group stocks from the Hong Kong Stock Exchange (HKSE) and subsequent re-listing on the Stock Exchange of Singapore (SSE). After the move the stocks' returns comove less with HKSE stocks and comove more with SSE stocks. Pirinsky and Wang (2006) show that when firms move the location of their headquarters, the returns of their stocks comove more with firms headquartered in the new location and less with stocks headquartered in the old location.

By looking at a one-time change in the index weights of Nikkei 225 and the cross-sectional differences between the Nikkei 225's price weights and value weights, Greenwood (2005, 2008) examines how index investors can impact stock returns. These papers provide evidence consistent with non-informational trading by index investors causing transitory distortions in prices. Our results for program traders on the NYSE provide direct evidence of a trading channel that causes price distortions.

There is also cross-sectional evidence on non-informational traders affecting individual stock returns. Coval and Stafford (2007) show that when mutual funds face redemptions, stocks they are heavily invested in decline and then recover. Andrade, Chang, and Seasholes (2008) show the order imbalances of a group of non-informational traders in Taiwan cause temporary price pressure in both the stocks with order imbalances and stocks most correlated with those stocks.

For order imbalances of groups of traders to have transitory effects on stock prices there 
must be frictions in the provision of liquidity. The transitory price effects can be thought of as compensation to the liquidity suppliers who take the other side of traders initiated by the non-informational traders. See Hendershott and Seasholes (2007), Kaniel, Saar, and Titman (2008), and Boehmer and Wu (2008) for empirical, cross-sectional, and idiosyncratic evidence on return predictability due to liquidity supplier trading. The last paper studies all categories of trading on the NYSE and find that program trading negatively predicts idiosyncratic returns at the individual stock level.

Under the assumption that all transactions occur with a market maker, total order imbalances (the sum of informed and non-informational order imbalances) can be inferred using an algorithm to sign trades. Chordia, Roll, and Subrahmanyam (2002) follow such an approach to examine the relations between returns and the trade-signed measure of total order imbalances. They find evidence supporting limited risk-bearing capacity on days with extreme negative returns and extreme negative order imbalances. Chordia and Subrahmanyam (2004) examine the relation between returns and the total order imbalance measure at the individual stock level. To study liquidity and market efficiency Chordia, Roll, and Subrahmanyam (2008) examine total order imbalances and five-minute returns.

The rest of this paper is as follows. Section 2 presents the model and derives regressions coefficients. Section 3 presents our data and provides overview statistics. Section 4 has the paper's main results based on regression analysis. We also estimate a vector autoregression using order imbalances and returns. Section 5 tests if the trading activity we use to measure order imbalances is consistent with non-informational liquidity trading. Section 6 looks at order imbalances around S\&P500 Index additions. Section 7 concludes.

\section{Theoretical Framework}

Our theoretical model with limited risk-bearing capacity and adverse selection is based on Subrahmanyam (1991b). The model leads to the hypotheses tested in the empirical section of this paper. There is a single traded asset and three dates denoted $t=\{1,2,3\}$. Trading takes place at time $t=2$. The asset pays a liquidating dividend equal to $s+\delta$ at $t=3$.

The market is populated by three types of traders: 1) A risk-neutral informed trader; 2) Liquidity traders, and 3) A finite number of symmetric and risk-averse arbitrageurs (market 
makers) with an aggregate coefficient of absolute risk aversion denoted $A_{m} \cdot{ }^{4}$ Just before trading at time $t=2$, part of the final dividend, denoted $s$, is revealed to all participants. ${ }^{5} \mathrm{In}$ addition, the informed trader receives a signal about the final dividend equal to $\delta+u$.

At time $t=2$ market participants trade. The informed trader chooses his optimal order which is denoted $x$. The liquidity traders place inelastic orders. Their net order imbalance is denoted $z$. The arbitrageurs trade against the total order imbalance $(x+z)$ and employ a pricing rule that is linear in the total order imbalance. As in Subrahmanyam (1991b), we impose the condition that they face competition such that their participation constraints bind. ${ }^{6}$ The model's random variables are assumed to be independently and normally distributed. The two parts of the dividend are $s \sim N\left(0, V_{S}\right)$ and $\delta \sim N\left(0, V_{\delta}\right)$. The informed trader's signal is $u \sim N\left(0, V_{U}\right)$. The liquidity traders' net order imbalance is $z \sim N\left(0, V_{Z}\right)$.

Given the linear pricing rule and publicly observed signal about the final dividend, the following lemma characterizes the equilibrium price at $t=2$ and the informed trader's orders. All proofs are in Appendix A.

Lemma 1. The informed trader submits order

$$
x=\frac{1}{2} \frac{(\delta+u) V_{\delta}}{\lambda\left(V_{\delta}+V_{U}\right)} .
$$

The arbitrageurs (market makers) observe a total order imbalance $(x+z)$ and the publicly revealed part of the final dividend ( $s$ ) at time $t=2$. They set the price of the risky asset to be $P_{2}=$ $s+\lambda(x+z)$. The price impact function " $\lambda$ " is the solution to:

$$
\lambda=\frac{V_{\delta}\left(A_{m} V_{\delta}^{2} V_{U}+4 \lambda V_{\delta}\left(V_{\delta}+V_{U}\right)+4 \lambda^{2} A_{m}\left(V_{\delta}+V_{U}\right)^{2} V_{Z}\right)}{2\left(V_{\delta}+V_{U}\right)\left(V_{\delta}^{2}+4 \lambda^{2} V_{\delta} V_{Z}+4 \lambda^{2} V_{U} V_{Z}\right)} .
$$

While $\lambda$ does not have a simple solution it is always positive. We set $P_{1} \equiv 0$ to start the model and define $P_{3} \equiv s+\delta$ which is the final dividend. Throughout this paper, we follow convention and define returns as price changes such that $R_{t+1} \equiv P_{3}-P_{2}$ and $R_{t} \equiv P_{2}-P_{1}$. Similarly, $Z_{t} \equiv z$.

To examine the relations between current returns, past returns, and past liquidity trading we focus on coefficients from three regressions: $i$ ) A univariate regression of returns on lagged

\footnotetext{
${ }^{4}$ The $N$ symmetric arbitrageurs each has a coefficient of absolute risk average equal to $A_{i}=\frac{A_{m}}{N}$.

${ }^{5}$ The public signal is added to ensure that time $t=2$ returns and liquidity trading are not perfectly correlated when there is no informed trading.

${ }^{6}$ Formalizing the exact assumptions needed for the market maker to earn his "autarky" utility is complex. See footnote 10 on p. 429 of Subrahmanyam (1991b).
} 
returns; ii) A univariate regression of returns on lagged liquidity trading; and iii) A bivariate regression of returns on lagged returns and lagged liquidity trading:

\begin{tabular}{ll}
$\#$ & Regression Equation \\
\hline$i)$ & $R_{t+1}=\beta_{R} R_{t}+\varepsilon_{t+1}$ \\
$i i)$ & $R_{t+1}=\beta_{Z} Z_{t}+\varepsilon_{t+1}$ \\
iii $)$ & $R_{t+1}=\beta_{R}^{*} R_{t}+\beta_{Z}^{*} Z_{t}+\varepsilon_{t+1}$
\end{tabular}

To determine the price at $t=2$ we substitute the informed trader's order from Lemma 1 into the linear pricing rule to get $P_{2}=s+\frac{(\delta+u) V_{\delta}}{2\left(V_{\delta}+V_{U}\right)}+\lambda z$. Using these prices, the following proposition gives the four regression coefficients.

Proposition 1. When there is both limited risk-bearing capacity and informed trading $\left(A_{m}>0\right.$ and $\left.V_{U}<\infty\right)$, the relations between returns, lagged returns, and lagged liquidity trading are:

$$
\begin{aligned}
\beta_{R} & =\frac{V_{\delta}^{2}-4 \lambda^{2} V_{Z}\left(V_{\delta}+V_{U}\right)}{V_{\delta}^{2}+4 V_{S}\left(V_{\delta}+V_{U}\right)+4 \lambda^{2} V_{Z}\left(V_{\delta}+V_{U}\right)}<0 \\
\beta_{Z} & =-\lambda<0 \\
\beta_{R}^{*} & =\frac{V_{\delta}^{2}}{V_{\delta}^{2}+4 V_{S}\left(V_{\delta}+V_{U}\right)}>0 \\
\beta_{Z}^{*} & =-\lambda\left(1+\beta_{R}^{*}\right)<0 .
\end{aligned}
$$

In a market with both limited risk-bearing capacity and informed trading, the autocovariance of returns $\operatorname{Cov}\left[R_{t+1}, R_{t}\right]$ is negative because the arbitrageurs/market makers require compensation for the risk associated with holding inventory from $t=2$ to $t=3$. Liquidity trading has a price impact at $t=2$ that is reversed at $t=3$, so the $\operatorname{Cov}\left[R_{t+1}, Z_{t}\right]$ is negative. The coefficient on liquidity trading from the bivariate regression, $\beta_{Z}^{*}$, is negative for the same reason as returns negatively covary with lagged liquidity trading.

The coefficient on lagged returns in the bivariate regression, $\beta_{R}^{*}$, differs in sign from the univariate regressions coefficient, $\beta_{R}$. This is because the negative autocovariance in returns is due to the limited risk-bearing capacity of the arbitrageurs/market makers. Putting liquidity trading in the regression makes the coefficient on lagged returns to be the impact of lagged returns conditional on the liquidity trading. Given that the price/return at time $t=2$ is a function of informed trading and liquidity trading, the lagged lagged return conditional on liquidity trading is a function of only informed trading. The informed trader only reveals 
part of his information via trading, so the return at $t=3$ is positively correlated with the informed trading at $t=2$.

To formulate how limited risk-bearing capacity and the presence of informed trading separately affect the regression coefficients, we study two cases: i) Unlimited risk-bearing capacity and informed trading; and $i i$ ) Limited risk-bearing capacity with no informed trading. The following two corollaries provide the regression coefficients for these two cases. Note that the case of both unlimited risk-bearing capacity and no informed trading makes trivial predictions. Prices only change due to public signals and all regression coefficients are zero.

Corollary 1. When there is unlimited risk-bearing capacity, $A_{m}=0$, the price impact function has the closed-form solution: $\lambda=\frac{V_{\delta}}{2 \sqrt{V_{Z}\left(V_{\delta}+V_{U}\right)}}$. The univariate and bivariate regression coefficients of returns on lagged returns and lagged liquidity trading are:

$$
\begin{aligned}
& \beta_{R}=0 \\
& \beta_{Z}=-\frac{V_{\delta}}{2 \sqrt{V_{Z}\left(V_{\delta}+V_{U}\right)}}<0 \\
& \beta_{R}^{*}=\frac{V_{\delta}^{2}}{V_{\delta}^{2}+4 V_{S}\left(V_{\delta}+V_{U}\right)}>0 \\
& \beta_{Z}^{*}=-\frac{V_{\delta}\left(1+\beta_{R}^{*}\right)}{2 \sqrt{V_{Z}\left(V_{\delta}+V_{U}\right)}}<0
\end{aligned}
$$

When the arbitrageurs are risk averse, stock returns are negatively autocorrelated $\left(\beta_{R}<0\right.$ in Regression $i)$. In the case of Corollary 1 , arbitrageurs are risk neutral $\left(A_{m}=0\right)$ and prices are a martingale $\left(\left(\beta_{R}=0\right.\right.$ in Regression $\left.i\right)$.

Corollary 2. When the informed trader's private signal consists entirely of noise, $V_{U}=\infty$, there is no informed trading and the price impact function has the closed-form solution: $\lambda=$ $\frac{1}{2} A_{m} V_{\delta}$. The univariate and bivariate regression coefficients of returns on lagged returns and lagged liquidity trading are:

$$
\begin{aligned}
\beta_{R} & =-\frac{A_{m}^{2} V_{\delta}^{2} V_{Z}}{4 V_{S}+A_{m}^{2} V_{\delta}^{2} V_{Z}}<0 \\
\beta_{Z} & =-\frac{1}{2} A_{m} V_{\delta}<0 \\
\beta_{R}^{*} & =0 \\
\beta_{Z}^{*} & =-\frac{1}{2} A_{m} V_{\delta}<0
\end{aligned}
$$

When there is no informed trading, the arbitrageurs need not worry about adverse selection. Price changes due to order imbalances arise solely from liquidity trading and are fully re- 
versed. Lagged returns conditional on lagged liquidity trading no longer provide information about informed trading, so $\beta_{R}^{*}=0$.

\section{[ Insert Table 1 About Here ]}

Table 1 summarizes the model's predictions. Comparing across rows and columns illustrates how the model's predictions differ depending on the two frictions: limited risk-bearing capacity and adverse selection.

\section{Data}

Our data span seven years (1,756 trading days) from January 1999 to December 2005. We obtain the data from a number of sources. The Center for Research in Security Prices (CRSP) provides daily prices, share volumes, and shares outstanding for all common stocks listed on the New York Stock Exchange (NYSE). We calculate daily midquote stock returns using the NYSE's Trades and Quotes (TAQ) database and the closing bid/ask quotes. The TAQ Master file allows us to match stock symbols with CUSIP numbers which are then matched with the NCUSIP field in the CRSP data. The use of midquote returns eliminates issues of bid-ask bounce that are present in transaction-based (CRSP) returns.

\section{[ Insert Table 2 About Here ]}

Table 2, Panel A shows overview statistics for the return data. Throughout the paper, we define "the market" using two groupings. The the first contains all CRSP-NYSE stocks. The second contains all S\&P500-NYSE stocks. Untabulated results show our data contain an average of 1,557 CRSP-NYSE stocks per day and 413 S\&P500-NYSE common stocks per day.

The full sample of CRSP-NYSE stocks has a slightly higher average return (2.204 basis points per day) than the S\&P500-NYSE stocks (1.794 basis points per day). Otherwise, returns from the two market aggregations appear similar. Finally, and also not tabulated, the index of CRSP-NYSE stocks based on daily midquote returns has a 0.944 correlation with the index based on closing-price returns. 


\subsection{Order Imbalance Data}

Our order imbalance data come from the NYSE's Consolidated Equity Audit Trail (CAUD) dataset. The data contain information about all executed NYSE trades including transaction: price, number of shares, amount, buyer account type, and seller account type. We focus on the Program Trader ("PT") account type. As discussed in the next paragraph, the NYSE's definition for PT makes it natural to think of these trades as portfolio trades. To minimize the influence of index arbitrage activity, we exclude data from the account type "Program Index Arbitrages Traders". A stock's order imbalance $\left(O I B_{i, t}\right)$ is defined as dollars bought minus dollars sold all divided by the market capitalization.

The NYSE defines program trading as the purchase or sale of 15 or more stocks having a total market value of $\$ 1$ million or more. With increased automation and the end of fixed commissions, brokers began offering the ability to execute program trades at very low cost. PT was closely studied after the 1987 market disruptions. Investors following strategies related to portfolio insurance sold S\&P500 futures as stock prices fell. This price pressure made futures cheaper than the underlying equities. Index arbitragers, who accounted for roughly a third of program trades at that time, transmitted this price pressure to the underlying stocks. The magnitude of this price pressure piqued the interest of regulators and academics in the links between intraday price discovery, volatility in the futures market, and volatility in the equity market - see Greenwald and Stein (1988). Initial program trading studies focus on the relationship between program trading, volatility, and futures prices - see Harris, Sofianos, and Shapiro (1994) and Hasbrouck (1996). In contrast, our data is designed to filter out the index arbitrage component of program trading and we examine PT's impact at interday horizons.

Since 1987 program trading by index traders has increased as the value of exchange-traded funds and index-linked derivatives has grown by hundreds of billions and trillions of dollars. Contracts based on the S\&P500 Index are the most heavily traded (ETFs, futures, and options). The advantages of program trading for index traders are its efficiency and low costs. $^{7}$ Program trades may be low cost because those trading a basket of securities can signal they have little or no information about the underlying stocks-Subrahmanyam (1991a).

Table 1, Panel B shows that program traders have been accumulating shares over the sample

\footnotetext{
${ }^{7}$ Bloomberg, "Program Trades Dominate NYSE 18 Years After Crash: Taking Stock," October 19, 2005, quotes the head of equity trading at the biggest manager of ETFs, Barclays Global Investors, as using program trading because "it increases efficiency and reduces costs."
} 
period. The average daily value is 0.258 basis points per day for the CRSP-NYSE stocks with a 0.695 standard deviation. Again, we see similar variables with the S\&P500-NYSE stocks. Figure 1 graphs our market-wide $O I B$ measure in units of fraction of market capitalization. Panel A shows the measure for the sample of CRSP-NYSE stocks. Panel B shows the measure for the S\&P500-NYSE stocks.

\section{[ Insert Figure 1 About Here ]}

During our sample period the total market capitalization of NYSE S\&P500 stocks is roughly $\$ 8$ trillion, making the 0.740 basis point standard deviation of $O I B$ correspond to about $\$ 600$ million. Days with imbalances that exceed three basis points of aggregate S\&P500 capitalization correspond to order imbalances of approximately $\$ 2.5$ billion. The volatility of $O I B_{t}$ appears somewhat higher at the beginning of the sample compared with the end of the sample.

As an additional test of program traders contemporaneously buying and selling across stocks in the market index, we conduct a principal component analysis. Calculating principal components requires that the time series be larger than the cross section, so as in Hasbrouck and Seppi (2001) we focus on the 28 NYSE-listed stocks in the Dow Jones Industrial Index. The first four principal components explain $15.15 \%, 5.54 \%, 4.87 \%$, and $4.34 \%$ of daily $O I B_{i, t}$ correlation. The first component is both economically and statistically significant indicating program traders tend to buy and sell stocks in the index at the same time.

Table 2, Panel C shows the program traders' fraction of daily market volume. The trading volume of program traders equals the dollar value of their buys plus sells. The program traders account for an average of $13.36 \%$ of market volume. This fraction is similar when looking only at S\&P500 stocks. ${ }^{8}$

\subsection{Correlations of Returns and $O I B$}

Table 3 reports the correlation of value-weighted market returns and order imbalances for all CRSP-NYSE stocks as well as only the S\&P500-NYSE stocks. The table also includes

\footnotetext{
${ }^{8}$ When the NYSE reports program trading as a percentage it typically reports program trading buys plus sells divided by total volume. If all trades were program trades, the NYSE would report that $200 \%$ of trading volume was due to program trading. Therefore, we calculate total volume as buy volume plus sell volume, which is twice the trading volume reported in TAQ or CRSP. Our approach leads to our program trading percentages being half as large as those reported by the NYSE.
} 
lagged returns and lagged order imbalances.

[ Insert Table 3 About Here ]

When looking at CRSP-NYSE stocks, returns are not autocorrelated. The AR(1) coefficient is 0.015 with a 0.53 p-value. On the other hand, $O I B_{t}$ has a positive $\mathrm{AR}(1)$ coefficient of 0.162 with a 0.00 p-value. The contemporaneous correlation between $R_{t}$ and $O I B_{t}$ is 0.530 and significant at all conventional levels. This indicates that PTs contemporaneously move prices or PTs engage in high-frequency (intraday) positive feedback trading. OIB is contrarian at a one-day lag with a -0.071 correlation between $O I B_{t}$ and $R_{t-1}$. Similar results hold for the S\&P500-NYSE stocks

Most intriguingly, $O I B_{t}$ negatively predicts market returns one day ahead as seen by the -0.064 correlation between $O I B_{t-1}$ and $R_{t}$. Some evidence of related effects is found in Chordia, Roll, and Subrahmanyam (2002). Their measure of $O I B_{t}$ constructed using a trade-signing algorithm does not predict market returns in their entire sample, but does predict S\&P500 returns the following day when $O I B_{t}$ and returns are both very negative on the same day.

\section{Empirical Results}

We test predictions developed in Section 2 and outlined in Table 1 by estimating the following three regressions: $i$ ) A univariate regression of returns on lagged returns; ii) A univariate regression of returns on the lagged order imbalances of the liquidity traders; and iii) A bivariate regression of returns on lagged returns and lagged order imbalances. Our empirical $O I B_{t}$ measure is used in place of the model's non-informational liquidity trades, $Z_{t}$ :

\begin{tabular}{ll}
$\#$ & Regression Equation \\
\hline$i)$ & $R_{t+1}=\beta_{R} R_{t}+\varepsilon_{t+1}$ \\
$i i)$ & $R_{t+1}=\beta_{o i b} O I B_{t}+\varepsilon_{t+1}$ \\
iii $)$ & $R_{t+1}=\beta_{R}^{*} R_{t}+\beta_{o i b}^{*} O I B_{t}+\varepsilon_{t+1}$
\end{tabular}

Table 4 contains the main empirical results of this paper. Predictions regarding the signs of regression coefficients are detailed in Proposition 1, Corollary 1 and, Corollary 2. We 
discuss the regression results in the context of specific null hypotheses. The null hypotheses are related to whether or not either of the two frictions (limited risk-bearing capacity and/or informed trading) are present:

[ Insert Table 4 About Here ]

Hypothesis 1. Frictionless Market: When there is unlimited risk-bearing capacity and no informed trading, there is no relation between returns, past return, and past liquidity trading: $\beta_{R}=\beta_{Z}=\beta_{R}^{*}=\beta_{Z}^{*}=0$.

The frictionless market case is trivial to analyze because prices only change due to public signals about future dividends. All regression coefficients are predicted to be zero. Table 4, Regression $i$ shows $\beta_{\text {oib }}=-9.800$ with a $-2.61 t$-statistic in the sample of CRSP-NYSE stocks. Table 3 shows the correlation between $R_{t}$ and $O I B_{t-1}$ is -0.064 with a $0.01 \mathrm{p}$-value. Either of these results allows us to reject the case of a frictionless market.

Hypothesis 2. Unlimited Risk-Bearing Capacity: If there is unlimited limited risk-bearing capacity, the coefficient from a regression of returns on lagged returns is zero: $\beta_{R}=0$.

The test of unlimited limited risk-bearing capacity is seen by comparing the predicted signs of regression coefficients across columns in the top row in Table 1 . The only coefficient that differs is $\beta_{R}$ from Regression $i$. Table 4 , Regression $i$ shows $\beta_{R}=0.015$ with a 0.58 $t$-statistic in the sample of CRSP-NYSE stocks. Table 3 shows the correlation between $R_{t}$ and $R_{t-1}$ is the same 0.015 with a $0.52 \mathrm{p}$-value. The finding that return autocorrelation is not statistically different from zero means we fail to reject the null hypothesis of unlimited risk-bearing capacity.

Hypothesis 3. No Informed Trading: If there is no informed trading, the coefficient on lagged returns from a bivariate regression of returns on lagged returns and lagged liquidity trading is zero: $\beta_{R}^{*}=0$.

The test of no informed trading is seen by comparing the predicted signs of the regression coefficients across rows in the first column in Table 1 . The only coefficient that differs is 
the bivariate regression coefficient $\beta_{R}^{*}$. Using CRSP-NYSE stocks, Table 4, Regression iii estimates $\beta_{R}^{*}=0.068$ with a $2.07 t$-statistic. The positive coefficient on returns, $\beta_{R}^{*}$, allows us to reject the null hypothesis of no informed trading.

Using the CRSP-NYSE stocks, the coefficients in Table 4 Regressions $i$, ii, and iii are $\beta_{R}=0.015$ with a $0.58 t$-statistic; $\beta_{\text {oib }}=-9.800$ with a -2.61 t-statistic; $\beta_{R}^{*}=0.068$ with a 2.07 $t$-statistic; and $\beta_{o i b}^{*}=-15.292$ with a -3.01 -statistic. The signs of these regressions coefficients fit the predictions of Corollary 1: $\beta_{R}=0, \beta_{\text {oib }}<0, \beta_{R}^{*}>0$, and $\beta_{\text {oib }}^{*}<0$. We repeat the three regressions using S\&P500-NYSE stocks and find similar results except that $\beta_{R}^{*}$ is positive at the $11 \%$-level.

Overall, our findings are consistent with the theoretical predictions based on the unlimited risk-bearing capacity and informed trading case in the upper right quadrant of Table 1 (Corollary 1). Put differently, we find evidence to support there being informed trading at the market level, but do not find evidence to support limited risk-bearing capacity at the market level.

\subsection{Vector Autoregression Results}

Table 3 shows order imbalances are positively autocorrelated and negatively correlated with lagged returns. To control for these effects, we estimate a vector autoregression using returns and $O I B_{t}$. In Equation 2, each of the $\boldsymbol{\Phi}_{k}$ matrices is dimension two-by-two and has four coefficients to be estimated. The errors are distributed: $\varepsilon_{t} \sim N[0, \Omega]$. The HQIC criteria indicates we should include four lags such that $K=4$ and $k=\{1,2,3,4\}$.

$$
\begin{gathered}
Y_{t}=c+\boldsymbol{\Phi}_{1} Y_{t-1}+\boldsymbol{\Phi}_{2} Y_{t-2}+\boldsymbol{\Phi}_{3} Y_{t-3}+\boldsymbol{\Phi}_{4} Y_{t-4}+\varepsilon_{t} \\
Y_{t}=\left[\begin{array}{c}
O I B_{t} \\
R_{t}
\end{array}\right] \quad c=\left[\begin{array}{c}
\alpha^{o i b} \\
\alpha^{r}
\end{array}\right] \quad \boldsymbol{\Phi}_{k}=\left[\begin{array}{cc}
\phi_{k, 1,1} & \phi_{k, 1,2} \\
\phi_{k, 2,1} & \phi_{k, 2,2}
\end{array}\right] \quad \varepsilon_{t}=\left[\begin{array}{c}
\varepsilon_{t}^{o i b} \\
\varepsilon_{t}^{r}
\end{array}\right]
\end{gathered}
$$

Table 5 reports Granger causality results. We show there exists bidirectional causality between returns and $O I B$. Most importantly, we show $O I B_{t}$ Granger causes returns. The relationship is significant at all conventional levels as the $39.02 \chi^{2}$ statistic shows. This along with the coefficients on lagged $O I B_{t}$ shows the predictability of market returns. Also, we see that returns Granger cause $O I B_{t}$ at all conventional levels of significance due to the negative feedback trading behavior by the program traders. 
[ Insert Table 5 About Here ]

A parsimonious way of capturing the net effects of all the coefficients in the VAR is to follow Hamilton (1994) and form orthogonalized impulse response functions (IRFs). The unit-shock IRF at horizon $t+s$ is denoted $\boldsymbol{\Phi}_{s}$ and comes from recursively solving the following: $\boldsymbol{\Psi}_{1}=\boldsymbol{\Phi}_{1}$ and $\boldsymbol{\Psi}_{s}=\boldsymbol{\Phi}_{1} \boldsymbol{\Psi}_{s-1}+\boldsymbol{\Phi}_{2} \boldsymbol{\Psi}_{s-2}+\ldots+\boldsymbol{\Phi}_{P} \boldsymbol{\Psi}_{s-K}$. The orthogonalized shock is obtained by factoring the covariance matrix of the error term $\Omega=\mathbf{P P}^{\prime}$ where $\mathbf{P}$ is lower diagonal. Denote the $j^{\text {th }}$ column of $\mathbf{P}$ as $P_{j}$. The IRF, or change to $Y_{t+s}$ in response to an orthogonalized shock at $t=0$, is given by $\Psi_{s} P_{j}$.

Figure 2, Panel A has four sub-panels. The focus of this paper is the lower-left panel. We see that a one standard deviation shock to $O I B_{t}$ leads to a -7.52 bp return the following day. The effect is short-lived and not significant after one day. The VAR results in Figure 2 show that the regression results in Table 4 are robust to a more general specification that controls for the autocorrelation in order imbalances and the negative correlation between order imbalances and lagged returns.

[ Insert Figure 2 About Here ]

Figure 2 shows the positive autocorrelation of $O I B_{t}$ in the top-left panel. The top-right panel gives evidence of the negative feedback trading. A one standard deviation shock to returns causes a 0.09 bp decrease in $O I B_{t}$. Figure 2, Panel B shows similar impulse response functions for the sample of S\&P500-NYSE stocks. The conditional autocorrelation is shown in the lower-right graph. We see that the ability of past return shocks to predict one-day ahead returns is positive and significant at the $5 \%$-level.

\section{$5 \quad$ Are Program Traders Uninformed?}

We calculate the returns and revenues associated with our portfolio trading imbalances. If $O I B_{t}$ represents non-informational order imbalances, we expect the trades to lose money. To calculate the returns associated with $O I B_{t}$, we follow standard calendar-time portfolio methodology and create separate "buy" and "sell" portfolios. For this paper, we assume a two day holding period which consists of the intra-day return on $t=0$, the return on $t+1$ and the return on $t+2$. 
We begin by calculating the value-weighted average buying price for program traders in aggregate, for each stock $i$, on each date $t=0$. The value-weighted price $\left(V W A P_{i, t=0}^{b u y}\right)$ is the dollar value of all shares bought by PT divided by number of shares bought by PT. The intra-day return on date $t=0$ is calculated using the closing midquote of bid and ask prices: $1+R_{i, t=0}^{b u y}=C l o s e_{i, t=0}^{\text {midq }} / V W A P_{i, t=0}^{b u y}$. To calculate holding period returns on date $t+1$ and $t+2$ we using midquote to midquote returns. Similar expressions hold for stocks sold.

The calendar-time buy portfolio return is the value weighted return of stocks in the portfolio on a given day. Value-weighting is determined by the number of shares originally bought by the program traders and the value of these shares. The value of the shares may change with market conditions but the number of shares does not.

Table 6, Panel A regresses the returns of the value-weighted Buy minus Sell portfolio on a constant, the market's excess returns, the Fama-French factors, and the Carhart momentum factor. We report results for both CRSP-NYSE stocks and for S\&P500-NYSE stocks. The "alpha" or constant in the regression is both econmically and statistically less than zero. For example, and alpha of -3 basis points (bp) corresponds to a loss of $7.85 \%$ per annum. The reported $t$-statistics are in the -15 range indicating significance at all conventional levels.

\section{[ Insert Table 6 About Here ]}

We also calculate the daily dollar revenues associated with $O I B$ trades. To calculate revenues we again focus on the amount bought and sold, of each stock, on each day. From the calendartime portfolios (above) we know the difference between the value-weighted average buying price and the closing midquote price. For example, the revenues associated with buying or selling a given stock on date $t$ and closing out the position on date $t+2$ are given by: ${ }^{9}$

$$
\begin{aligned}
& \operatorname{Rev}_{i, t+2}^{\text {buy }}=\operatorname{Amount}(\$)_{i, t=0}^{\text {buy }} \times\left[\left(1+R_{i, t=0}^{\text {buy }}\right) \cdot\left(1+R_{i, t+1}^{\text {midq }}\right) \cdot\left(1+R_{i, t+2}^{\text {midq }}\right)-1\right] \\
& \operatorname{Rev}_{i, t+2}^{\text {sell }}=\operatorname{Amount}(\$)_{i, t=0}^{\text {sell }} \times\left[\left(1+R_{i, t=0}^{\text {sell }}\right) \cdot\left(1+R_{i, t+1}^{\text {midq }}\right) \cdot\left(1+R_{i, t+2}^{\text {midq }}\right)-1\right] \\
& \operatorname{Rev}_{i, t+2}=\operatorname{Rev}_{i, t+2}^{\text {buy }}-\operatorname{Rev}_{i, t+2}^{\text {sell }}
\end{aligned}
$$

We sum revenues across stocks on the same day to form a single time series of revenues.

\footnotetext{
${ }^{9}$ This calculation is equivalent to how generally accepted accounting principles have financial firms calculate gross trading revenues where open positions are marked to a market value (in our case the closing quote midpoint).
} 
Results are shown in Table 7, Panel B.

On date $t$, program traders buy slightly above the closing midquote and sell slightly below the same value (on average). The results show an average daily revenue of $\$-286,016$ with a $-3.32 t$-statistic. Therefore, there is no evidence that program traders make money at intraday horizons.

Consistent with program trading negatively predicting future market returns, if stocks are held an additional day or two, mark-to-market losses increase significantly. The average daily revenue is $\$-1,914,493$ with a -7.47 -statistic if positions are closed out at the end of date $t+1$. The average daily revenue is $\$-2,237,162$ if positions are closed out on date $t+2$. Table 7 reports $t$-statistics based on Newey-West standard errors with five lags. Similar results hold for the sample of S\&P500-NYSE stocks. The results in this section show that program traders lose money, so it is natural to think of program trading as non-informational.

\section{Index Additions}

Studies of additions to the the S\&P500 Index often cite non-informational traders who trade all stocks in the S\&P500 Index as the explanation for their results. Program trading is by definition trading in a large basket of stocks and the prior section establishes that program trading is non-informational liquidity trading. Therefore, program trading order imbalances provide a natural way to examine if there is a relationship between non-informational traders and results from studies of changes to the S\&P500 Index.

To examine whether program trading changes after a stock joins the S\&P500 Index we construct a sample of 90 NYSE-listed additions starting in January 2000 and ending December 2004 (skipping a year at the beginning and end of the same in order to estimate the comovement results described below). Of these, the year 2000 has the most additions (31), while the year 2003 has the fewest (5). Our events occur on 57 different days. Four days have two additions, one day has four additions, and one day has five additions.

In results not tabulated we compare our additions to existing event studies. In our sample, prices jump up $4 \%$ on average on the announcement date and then hold steady. This increase is comparable to Chen, Noronha, and Singal (2004) for their 1989 to 2000 sample period. Consistent with Hegde and McDermott (2003), we measure an increase in turnover and decline in spreads around additions. Both are statistically significant. Finally we measure 
an increase in return comovement that similar to results in Vijh (1994) and Barberis, Shleifer, and Wurgler (2005).

\section{[ Insert Figure 3 About Here ]}

The above papers on $\mathrm{S} \& \mathrm{P}$ additions posit that their results are due to a group of traders who trade all stocks in the S\&P500 Index. To link our order imbalance measure to index additions we first calculate the average level of daily program trading during the $t=[-20,+20]$ event window. Figure 3 highlights the difference between aligning events by announcement dates and by effective dates. ${ }^{10}$ The upper-right graph shows that program traders experience a sharp increase in turnover on the last day before a stock joins the index. The lower right graph shows that the increased turnover is due (partially) to program traders accumulating shares of the added stock. Between $t=-20$ and $t=+20$, the program traders acquire approximate $1.1 \%$ of the company's shares. Table 7 , Panel A provides the some of the numbers behind the Figure 3 .

[ Insert Table 7 About Here ]

Vijh (1994) and Barberis, Shleifer, and Wurgler (2005) cite non-informational traders focusing on the S\&P500 stocks as being the source of the changes in comovement upon addition to the index. To test this we first measure the change in $O I B_{i, t}$ comovement from the $[-250,-51]$ interval to the $[+51,+250]$ interval. We start with a univariate regression to quantify changes in comovement. Regression (4) is performed separately for each of the event stocks both before and after the addition. We record the $\beta_{s p 500, i}^{o i b}$ and $R^{2}$ for each regression before comparing pre- and post-event values. For all comovement regressions, $O I B_{s p 500, t}$ is the market-capitalization weighted average of $O I B_{i, t}$ across all S\&P500-NYSE stocks not including stock $i$.

$$
O I B_{i, t}=\alpha_{i}+\beta_{s p 500, i}^{o i b}\left(O I B_{s p 500, t}\right)+\varepsilon_{i, t}
$$

Table 7, Panel B show that both $R^{2}$ and $\beta_{s p 500}^{o i b}$ increase after a stock is added to the S\&P500 Index. These increases are both statistically significant with 4.03 and $3.86 t$-statistics respectively. Both the $\beta_{s p 500}^{o i b}$ and the $R^{2}$ show near three-fold increases post addition.

\footnotetext{
${ }^{10}$ The last date before a stock joins the index is called the "effective date" and is available from Standard and Poor's website. Each event's "announcement date" is originally obtained from Jeffrey Wurgler's website and then modified by searching news releases. The average difference between the two dates is 7.03 trading days. The standard deviation of the difference is 6.79 days.
} 
The right columns of Table 7, Panel B show results of a bivariate OIB regression:

$$
O I B_{i, t}=\alpha_{i}+\beta_{s p 500, i}^{o i b}\left(O I B_{s p 500, t}\right)+\beta_{n o n s p 500, i}^{o i b}\left(O I B_{n o n s p 500, t}\right)+\varepsilon_{i, t} .
$$

As in Barberis, Shleifer, and Wurgler (2005), upon addition the $\beta_{s p 500}^{o i b}$ increases and the $\beta_{\text {nonsp } 500}^{\text {oib }}$ decreases. Both the increase and the decrease are statistically significant. Our OIB comovement results show that upon addition to the S\&P500 Index, a stock's order imbalances start to comove more with the order imbalances of other S\&P500 stocks. This, taken together with the increase in PT volume and the large positive cumulative PT OIB, suggests that PT OIB may be a source of increased return comovement.

To more directly link the post-addition change in return comovement with the post-addition change in order imbalances we estimate a "cross- $\beta$ " from the regression:

$$
R_{i, t}=\alpha_{i}+\beta_{s p 500, i}^{r, o i b}\left(O I B_{s p 500, t}\right)+\varepsilon_{i, t} .
$$

Table 7, Panel $\mathrm{C}$ provides more direct evidence of a link between return comovement being caused by program trading. The $R^{2}$ of the cross-regression more than doubles from 0.030 to 0.073 with a 4.55 t-statistic. The cross-beta almost doubles from 44.0 to 70.1 with a 3.25 t-statistic. ${ }^{11}$

\section{Conclusion}

If non-informational traders can cause changes in individual securities returns, can these traders affect market returns? This paper answers this question affirmatively. A theoretical model is used to characterize two reasons why arbitrageurs fail to eliminate the effects of noninformational trades: a) arbitrageurs have limited risk-bearing capacity; and b) arbitrageurs worry about adverse selection when trading against orders.

Regression analysis finds that the adverse selection story (not limited risk-bearing capacity) provides a better description of the relations between returns, lagged returns, and lagged non-informational order imbalances. Our model and empirical tests examine the simple

\footnotetext{
${ }^{11}$ Untabulated results calculate the cross-sectional correlation of the change in return comovement with the change in $O I B$ comovement. The Pearson correlation coefficient of $\Delta R_{i}^{2}$ (returns) and $\Delta R_{i}^{2}(O I B)$ is 0.214 with a $0.09 \mathrm{P}$ value. Thus, there is both a time series and cross-sectional relation between changes in return comovement and the $O I B$ comovement.
} 
market-wide arbitrage strategy of market-wide liquidity provision. The lack of evidence for limited risk-bearing capacity for this strategy suggests that specialization is empirically important for the Shleifer and Vishny (1997) limits to arbitrage arguments. ${ }^{12}$

\footnotetext{
${ }^{12}$ At least during our sample period in U.S. markets. It is interesting to note that that there is evidence of limited risk-bearing capacity beginning with the recent financial crisis: the autocorrelation of daily returns on the S\&P500 Index becomes significantly negative, close to -0.15 in both 2007 and 2008 . This recent evidence on limit-risk bearing capacity suggests less capital being devoted to market liquidity provision, possibly due to wealth affects.
} 


\section{References}

[1] Admati, Anat, and Paul Pfleiderer, 1988, A theory of intraday patterns: volume and price variability, Review of Financial Studies 1, 3-40.

[2] Amihud, Yakov, and Haim Mendelson, 1980, Dealership market: Market making with inventory, Journal of Financial Economics 8, 31-54.

[3] Andrade, Sandro, Charles Chang, and Mark Seasholes, 2008, Trading imbalances, predictable reversals, and cross-stock price pressure, Journal of Financial Economics, 88(2) May, 406-423.

[4] Bessembinder, Hendrik, 2003, Issues in assessing trade execution costs, Journal of Financial Markets, Journal of Financial Markets 6, 233-257.

[5] Boehmer, Ekkehart, and Julie Wu, 2008, Order flow and prices, working paper.

[6] Chan, Kalok, Allaudeen Hameed, and Sie Lau, 2003, What if trading location is different from business location? Evidence from the Jardine Group, Journal of Finance 58, 12211246.

[7] Chen, Honghui, Gregory Noronha, and Vijay Singal, 2004, The price response to S\&P 500 index additions and deletions: Evidence of Asymmetry and a new explanation, Journal of Finance 59, 1901-1929.

[8] Chordia, Tarun, Richard Roll, and Avanidhar Subrahmanyam, 2002, Order imbalance, liquidity and market returns, Journal of Financial Economics 65, 111-130.

[9] Chordia, Tarun, Richard Roll, and Avanidhar Subrahmanyam, 2008, Liquidity and market efficiency, Journal of Financial Economics 87, 249-268.

[10] Chordia, Tarun, and Avanidhar Subrahmanyam, 2004, Order imbalances and individual stock returns: theory and evidence, Journal of Financial Economics 72, 485-518.

[11] Coval, Joshua, and Erik Stafford, 2007, Asset fire sales (and purchases) in equity markets, Journal of Financial Economics 86, 479-512.

[12] Evans, Martin, and Richard Lyons, 2002, Order flow and exchange rate dynamics, Journal of Political Economy, 110, 170-180.

[13] Evans, Martin, and Richard Lyons, 2005, A new micro model of exchange rate dynamics, Working paper. 
[14] Evans, Martin, and Richard Lyons, 2008, Forecasting exchange rates and fundamentals with order flow, Working paper.

[15] Froot, Kenneth and Emil Dabora, 1999, How are stock prices affected by the location of trade? Journal of Financial Economics 53, 189-216.

[16] Greenwald, Bruce and Jeremy Stein, 1988, The task force report: The reasoning behind the recommendations, Journal of Economic Perspectives 2, 3-23.

[17] Greenwood, Robin, 2005, Short- and long-term demand curves for stocks: Theory and evidence on the dynamics of arbitrage, Review of Financial Studies 75, 607-649.

[18] Greenwood, Robin, 2008, Excess comovement of stock returns: Evidence from crosssectional variation in Nikkei 225 weights, Review of Financial Studies 21, 1153-1186.

[19] Grossman, Sanford, and Merton Miller, 1988, Liquidity and market structure, Journal of Finance 43, 617-633.

[20] Hamilton, James D., 1994, Time series analysis, Princeton University Press.

[21] Harris, Lawrence, George Sofianos, and James Shapiro, 1994, Program trading and intraday volatility, Review of Financial Studies 7, 653-685.

[22] Hasbrouck, Joel, 1996, Order characteristics and stock price evolution: an application to program trading, Journal of Financial Economics 41, 129-149.

[23] Hasbrouck, Joel, and Duane Seppi, 2001, Common factors in prices, order flows, and liquidity, Journal of Financial Economics 59, 383-411.

[24] Hegde, Shantaram, and John McDermott, 2003, The liquidity effect of revisions to the S\&P 500 index: an empirical analysis, Journal of Financial Markets 6, 413-459.

[25] Hendershott, Terrence, and Mark Seasholes, 2007, Market maker inventories and stock prices, American Economic Review 97, 210-214.

[26] Ho, Thomas, and Hans Stoll, 1981, Optimal dealer pricing under transactions and return uncertainty, Journal of Financial Economics 9, 47-73.

[27] Kaniel, Ron, Gideon Saar, and Sheridan Titman, 2008, Individual investor trading and stock returns Journal of Finance 63, 273-310.

[28] Kyle, Albert, 1985, Continuous auctions and insider trading, Econometrica 53, 13151335. 
[29] Madhavan, Ananth, and Seymour Smidt, 1993, An analysis of daily changes in specialist inventories and quotations, Journal of Finance 48, 1595-1628.

[30] Pirinsky, Christo, and Qinghai Wang, 2006, Does corporate headquarters location matter for stock returns? Journal of Finance 61, 1991-2015.

[31] Shleifer, Andrei, and Robert Vishny, 1997, The limit of arbitrage, Journal of Finance $52,35-55$.

[32] Subrahmanyam, Avanidhar, 1991a, A theory of trading in stock index futures, Review of Financial Studies 4(1), 17-51.

[33] Subrahmanyam, Avanidhar, 1991b, Risk aversion, market liquidity, and price efficiency, Review of Financial Studies 4(3), 417-441. 


\section{Appendix A: Proofs}

Proof of Lemma 1: The proof follows from the usual arguments about the properties of normal random variables and the market maker's inference problem. Our set up is similar to Subrahmanyam (1991b). The trading intensity variable, $t$, is the standard Kyle $\beta$ from a model with noisy signals — see, for example, Admati and Pfleiderer (1988). Equation (7) below is comparable to Equation (15) from Subrahmanyam (1991b) except we set $k=1$ and allow $V_{\delta}$ to have value other than one.

$$
\lambda=V_{\delta} \frac{t+\left(A_{m} / 2\right)\left(t^{2} V_{U}+V_{Z}\right)}{t^{2}\left(V_{\delta}+V_{U}\right)+V_{Z}}
$$

Where $t \equiv \frac{1}{2} \frac{V_{\delta}}{\lambda\left(V_{\delta}+V_{U}\right)}$. Substituting the expression for $t$ into Equation (7) obtains the expression for $\lambda$ shown in Lemma 1.

Proof of Proposition 1: Returns and non-informational order imbalances are:

$$
\begin{aligned}
R_{t+1} & =s+\delta-(s+\lambda(x+z)) \\
R_{t} & =s+\lambda(x+z) \\
Z_{t} & =z
\end{aligned}
$$

Using the above expressions and $x=\frac{1}{2} \frac{(\delta+u) V_{\delta}}{\lambda\left(V_{\delta}+V_{u}\right)}$, the covariances are:

$$
\begin{aligned}
& \operatorname{Cov}\left[R_{t+1}, R_{t}\right]=\frac{1}{4} \frac{V_{\delta}^{2}}{\left(V_{\delta}+V_{U}\right)}-\lambda^{2} V_{Z} \\
& \operatorname{Cov}\left[R_{t+1}, Z_{t}\right]=-\lambda V_{Z}
\end{aligned}
$$

Showing that $\operatorname{Cov}\left[R_{t+1}, R_{t}\right]<0$ (and therefore $\beta_{R}<0$ ) is straightforward. We know that the $\lambda$ is increasing in risk aversion: $\frac{\partial \lambda}{\partial A_{m}}>0$. Some algebra shows the standard result that when $A_{m}=0$ prices are a martingale: $\operatorname{Cov}\left[R_{t+1}, R_{t}\right]=0$. Thus, when $A_{m}>0$ returns are strictly negatively autocorrelated.

Using the above expressions, the variance of returns is:

$$
\operatorname{Var}\left[R_{t}\right]=V_{S}+\frac{1}{4} \frac{V_{\delta}^{2}}{\left(V_{\delta}+V_{Z}\right)}+\lambda^{2} V_{Z}
$$


The coefficients the from bivariate regression $R_{t+1}=\beta_{R}^{*} R_{t}+\beta_{Z}^{*} Z_{t}+\varepsilon_{t+1}$ are:

$$
\begin{aligned}
\beta_{R}^{*} & =\frac{\operatorname{Cov}\left[R_{t+1}, Z_{t}\right] \cdot \operatorname{Cov}\left[Z_{t}, R_{t}\right]-\operatorname{Cov}\left[R_{t+1}, R_{t}\right] \cdot V_{Z}}{\left(\operatorname{Cov}\left[Z_{t}, R_{t}\right]\right)^{2}-\operatorname{Var}\left[R_{t}\right] V_{Z}} \\
\beta_{Z}^{*} & =\frac{\operatorname{Cov}\left[R_{t+1}, R_{t}\right] \cdot \operatorname{Cov}\left[Z_{t}, R_{t}\right]-\operatorname{Cov}\left[R_{t+1}, Z_{t}\right] \cdot \operatorname{Var}\left[R_{t}\right]}{\left(\operatorname{Cov}\left[Z_{t}, R_{t}\right]\right)^{2}-\operatorname{Var}\left[R_{t}\right] V_{Z}}
\end{aligned}
$$

Use the covariance and variance terms from above. Also, note that $\operatorname{Cov}\left[R_{t}, Z_{t}\right]=\lambda V_{Z}$. We get:

$$
\begin{aligned}
& \beta_{R}^{*}=\frac{V_{\delta}^{2}}{V_{\delta}^{2}+4 V_{\delta} V_{S}+4 V_{S} V_{U}} \\
& \beta_{Z}^{*}=-\lambda\left(1+\beta_{R}^{*}\right)
\end{aligned}
$$

Proofs of the Corollary 1 and Corollary 2 follow from solving for $\lambda$ under the assumptions $V_{U}=\infty$ and $A_{m}=0$ and substituting into results given in Proposition 1. 


\section{Table 1 \\ Model Predictions}

The table outlines the model's predictions for three regressions: i) A univariate regression of returns on lagged returns; ii) A univariate regression of returns on the lagged order imbalances of the non-informational traders; iii) A bivariate regression of returns on lagged returns and lagged order imbalances. The table presents predictions for when the informed trader has information about future dividends and when the informed trader has information about future dividends has no information about future dividends. The table also presents predictions for when the arbitrageurs have limited risk-bearing capacity and when the arbitrageurs have unlimited risk-bearing capacity.

$$
\begin{array}{ll}
\text { i) } & R_{t+1}=\beta_{R} R_{t}+\varepsilon_{t+1} \\
\text { ii) } & R_{t+1}=\beta_{Z} Z_{t}+\varepsilon_{t+1} \\
\text { iii) } & R_{t+1}=\beta_{R}^{*} R_{t}+\beta_{Z}^{*} Z_{t}+\varepsilon_{t+1}
\end{array}
$$

\begin{tabular}{|c|c|c|}
\hline & $\begin{array}{c}\text { Limited } \\
\text { Risk-Bearing } \\
\text { Capacity }\end{array}$ & $\begin{array}{c}\text { Unlimited } \\
\text { Risk-Bearing } \\
\text { Capacity }\end{array}$ \\
\hline $\begin{array}{c}\text { Informed } \\
\text { Trading }\end{array}$ & 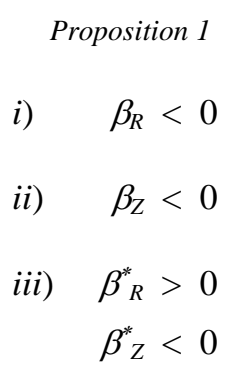 & $\begin{aligned} \text { Corollary } 1 & \\
\text { i) } & \beta_{R}=0 \\
\text { ii) } & \beta_{Z}<0 \\
\text { iii) } \quad & \beta_{R}^{*}>0 \\
& \beta_{Z}^{*}<0\end{aligned}$ \\
\hline $\begin{array}{c}\text { No } \\
\text { Informed } \\
\text { Trading }\end{array}$ & $\begin{aligned} & \text { Corollary } 2 \\
\text { i) } & \beta_{R}<0 \\
\text { ii) } & \beta_{Z}<0 \\
\text { iii) } & \beta_{R}^{*}=0 \\
& \beta_{Z}^{*}<0\end{aligned}$ & $\begin{aligned} \text { Frictionless Market } & \\
\text { i) } & \beta_{R}=0 \\
\text { ii) } & \beta_{Z}=0 \\
\text { iii) } & \beta_{R}^{*}=0 \\
& \beta_{Z}^{*}=0\end{aligned}$ \\
\hline
\end{tabular}




\section{Table 2}

\section{Overview Statistics}

Table shows overview statistics of daily market level variables. Panel A shows returns. Panel B shows order imbalances of program traders. Panel C shows fraction of daily volume. "CRSP" is the value-weighted index of NYSE-listed stocks from the Center for Research in Security Prices. "S\&P500" is comprised of NYSE-listed stocks from the Standard and Poor's index of 500 leading companies in the U.S. economy. Returns based on the closing mid-points of the bid and ask prices.

\section{Panel A: Returns $\left(\boldsymbol{R}_{t}\right)$}

\begin{tabular}{lccccc} 
& $\begin{array}{c}\text { Average } \\
(\mathbf{b p )}\end{array}$ & Stdev & $\mathbf{2 5}^{\text {th }}-\mathbf{P t i l e}$ & $\mathbf{7 5}^{\text {th }}-\mathbf{P t i l e}$ & \# of Days \\
\hline CRSP & 2.204 & $1.057 \%$ & $-0.597 \%$ & $0.590 \%$ & 1,756 \\
S\&P500 & 1.794 & $1.078 \%$ & $-0.612 \%$ & $0.585 \%$ & 1,756
\end{tabular}

Panel B: Order Imbalances $\left(O^{\prime} B_{t}\right)$

\begin{tabular}{lccccc} 
& $\begin{array}{c}\text { Average } \\
\text { (bp) }\end{array}$ & $\begin{array}{c}\text { Stdev } \\
\text { (bp) }\end{array}$ & $\begin{array}{c}\mathbf{2 5} \\
\text { (bp) }\end{array}$ & $\begin{array}{c}\mathbf{7 5}^{\text {th }}-\text { Ptile } \\
\text { (bp) }\end{array}$ & \# of Days \\
\hline CRSP & 0.258 & 0.695 & -0.156 & 0.622 & 1,756 \\
S\&P500 & 0.231 & 0.740 & -0.181 & 0.608 & 1,756
\end{tabular}

Panel C: Fraction of Daily Market Volume

\begin{tabular}{lccccc} 
& $\begin{array}{c}\text { Average } \\
(\mathbf{\%})\end{array}$ & $\begin{array}{c}\text { Stdev } \\
\mathbf{( \% )}\end{array}$ & $\begin{array}{c}\mathbf{2 5}^{\text {th }} \mathbf{- P t i l e} \\
\mathbf{( \% )}\end{array}$ & $\begin{array}{c}\mathbf{7 5}^{\text {th }} \mathbf{- P t i l e} \\
\mathbf{( \% )}\end{array}$ & \# of Days \\
\hline CRSP & 13.36 & 4.36 & 9.53 & 16.86 & 1,756 \\
S\&P500 & 13.41 & 4.11 & 9.85 & 16.60 & 1,756
\end{tabular}


Table 3

\section{Correlation Coefficients}

Table shows correlation coefficients of market-level returns and order imbalances. We consider two definitions of marketlevel. The first contains all CRSP-NYSE stocks. The second contains all S\&P500-NYSE stocks. Returns are based on the closing mid-points of the bid and ask prices. P-values are shown in parentheses.

\begin{tabular}{|c|c|c|c|c|c|c|c|c|c|}
\hline & \multicolumn{4}{|c|}{ CRSP } & \multicolumn{4}{|c|}{ S\&P500 } \\
\hline & & $\boldsymbol{R}_{t}$ & $R_{t-1}$ & $O I B_{t}$ & OIB $_{t-1}$ & $\boldsymbol{R}_{t}$ & $R_{t-1}$ & $\mathrm{OIB}_{t}$ & $O I B_{t-1}$ \\
\hline \multirow{4}{*}{ CRSP } & $R_{t}$ & 1.000 & & & & & & & \\
\hline & $R_{t-1}$ & $\begin{array}{c}0.015 \\
(0.53)\end{array}$ & 1.000 & & & & & & \\
\hline & $O I B_{t}$ & $\begin{array}{c}0.530 \\
(0.00)\end{array}$ & $\begin{array}{c}-0.071 \\
(0.00)\end{array}$ & 1.000 & & & & & \\
\hline & $O I B_{t-1}$ & $\begin{array}{c}-0.064 \\
(0.01)\end{array}$ & $\begin{array}{c}0.530 \\
(0.00)\end{array}$ & $\begin{array}{l}0.162 \\
(0.00)\end{array}$ & $\begin{array}{c}1.000 \\
----\end{array}$ & & & & \\
\hline \multirow{4}{*}{$\begin{array}{c}\text { S\&P } \\
500\end{array}$} & $\boldsymbol{R}_{t}$ & $\begin{array}{l}0.997 \\
(0.00)\end{array}$ & $\begin{array}{l}0.002 \\
(0.931)\end{array}$ & $\begin{array}{l}0.535 \\
(0.00)\end{array}$ & $\begin{array}{c}-0.074 \\
(0.00)\end{array}$ & $\begin{array}{c}1.000 \\
----\end{array}$ & & & \\
\hline & $R_{t-1}$ & $\begin{array}{c}0.015 \\
(0.54)\end{array}$ & $\begin{array}{l}0.997 \\
(0.00)\end{array}$ & $\begin{array}{c}-0.069 \\
(0.00)\end{array}$ & $\begin{array}{c}0.535 \\
(0.00)\end{array}$ & $\begin{array}{c}0.002 \\
(0.94)\end{array}$ & 1.000 & & \\
\hline & $O I B_{t}$ & $\begin{array}{l}0.465 \\
(0.00)\end{array}$ & $\begin{array}{c}-0.062 \\
(0.01)\end{array}$ & $\begin{array}{l}0.978 \\
(0.00)\end{array}$ & $\begin{array}{c}0.169 \\
(0.00)\end{array}$ & $\begin{array}{c}0.476 \\
(0.00)\end{array}$ & $\begin{array}{c}-0.061 \\
(0.01)\end{array}$ & 1.000 & \\
\hline & $O I B_{t-1}$ & $\begin{array}{c}-0.068 \\
(0.00)\end{array}$ & $\begin{array}{l}0.465 \\
(0.00)\end{array}$ & $\begin{array}{l}0.165 \\
(0.00)\end{array}$ & $\begin{array}{c}0.978 \\
(0.00)\end{array}$ & $\begin{array}{c}-0.077 \\
(0.00)\end{array}$ & $\begin{array}{l}0.476 \\
(0.00)\end{array}$ & $\begin{array}{c}0.175 \\
(0.00)\end{array}$ & $\begin{array}{c}1.000 \\
---\end{array}$ \\
\hline
\end{tabular}




\section{Table 4 \\ Regression Analysis}

Table results of regressions analysis. We consider three regressions: i) A univariate regression of returns on lagged returns; ii) A univariate regression of returns on the lagged order imbalances of non-informational traders; and iii) A bivariate regression of returns on lagged returns and lagged order imbalances. We consider two samples of stocks. The first contains all CRSP-NYSE stocks. The second contains all S\&P500-NYSE stocks. T-statistics are shown in parentheses and are based on Newey-West standard errors.

$$
\begin{array}{ll}
\text { i) } & R_{t+1}=\alpha+\beta_{R} R_{t}+\varepsilon_{t+1} \\
\text { ii) } & R_{t+1}=\alpha+\beta_{o i b} O I B_{t}+\varepsilon_{t+1} \\
\text { iii) } & R_{t+1}=\alpha+\beta_{R}^{*} R_{t}+\beta_{o i b}^{*} O I B_{t}+\varepsilon_{t+1}
\end{array}
$$

\begin{tabular}{|c|c|c|c|c|c|c|}
\hline & \multicolumn{3}{|c|}{ CRSP } & \multicolumn{3}{|c|}{ S\&P500 } \\
\hline & i & ii & iii & i & ii & iii \\
\hline $\begin{array}{r}\text { Const (bp) } \\
(T-\text {-stat) }\end{array}$ & $\begin{array}{l}2.118 \\
(0.87)\end{array}$ & $\begin{array}{l}4.681 \\
(1.91)\end{array}$ & $\begin{array}{l}5.946 \\
(2.49)\end{array}$ & $\begin{array}{l}1.730 \\
(0.70)\end{array}$ & $\begin{array}{l}4.306 \\
(1.74)\end{array}$ & $\begin{array}{l}5.008 \\
(2.08)\end{array}$ \\
\hline $\begin{array}{r}\boldsymbol{R}_{\text {CRSP, }} \\
\text { (T-stat) }\end{array}$ & $\begin{array}{l}0.015 \\
(0.58)\end{array}$ & & $\begin{array}{l}0.068 \\
(2.07)\end{array}$ & & & \\
\hline $\begin{array}{r}\boldsymbol{O I B}_{\text {CRSP, }} \\
\text { (T-stat) }\end{array}$ & & $\begin{array}{c}-9.800 \\
(-2.61)\end{array}$ & $\begin{array}{c}-15.292 \\
(-3.04)\end{array}$ & & & \\
\hline $\begin{array}{c}\boldsymbol{R}_{\boldsymbol{S \& P}, \boldsymbol{t}} \\
\text { (T-stat) }\end{array}$ & & & & $\begin{array}{l}0.002 \\
(0.07)\end{array}$ & & $\begin{array}{l}0.050 \\
(1.60)\end{array}$ \\
\hline $\begin{array}{r}\boldsymbol{O I B}_{S \& P, t} \\
\text { (T-stat) }\end{array}$ & & & & & $\begin{array}{c}-11.167 \\
(-3.13)\end{array}$ & $\begin{array}{c}-14.609 \\
(-3.31)\end{array}$ \\
\hline \# of Obs & 1,755 & 1,755 & 1,755 & 1,755 & 1,755 & 1,755 \\
\hline
\end{tabular}


Table 5

Vector Autoregression of Order Imbalances and Returns

Results of Granger-causality tests are reported for vector autogressions. The two dependent variables included marketlevel order imbalances and returns. The right-hand side variables include four lags of these variables. Order imbalance (OIB) for each stock is program trading shares bought minus shares sold normalized by shares outstanding. OIB is aggregated across stocks using market capitalization weights. Returns are value-weighted and based on the closing midpoints of the bid and ask prices.

Panel A: CRSP

\begin{tabular}{ccccc} 
Var 1 & Causes & Var 2 & $\chi^{2}$ & P-Value \\
\hline $\boldsymbol{R}_{\text {crsp }}$ & $\rightarrow$ & OIB $_{\text {crsp }}$ & 39.02 & 0.000 \\
OIB $_{\text {crsp }}$ & $\rightarrow$ & $\boldsymbol{R}_{\text {crsp }}$ & 17.50 & 0.002
\end{tabular}

Panel B: S\&P500

\begin{tabular}{ccccc} 
Var 1 & Causes & Var 2 & $\chi^{2}$ & P-Value \\
\hline $\boldsymbol{R}_{s p 500}$ & $\rightarrow$ & OIB $_{s p 500}$ & 29.83 & 0.000 \\
OIB $_{s p 500}$ & $\rightarrow$ & $\boldsymbol{R}_{s p 500}$ & 18.90 & 0.001
\end{tabular}




\section{Table 6 \\ Program Trading Returns and Revenues}

This table shows returns and revenues associated with program trading. Panel A calculates average daily calendar-time portfolio returns based on transactions of program traders. We mimic the traders buys and sells on each date $t$ and unwind positions at closing mid-point prices on date $t+2$. Panel B shows average daily revenues based on the purchases and sales of stocks by program traders. We assume all positions are either closed out on the day stocks are purchased or sold (date $t$ ), at the end of the following day $(t+1)$, or two days later $(t+2)$. In both panels, purchase and sale prices are calculated using the value-weighted average price paid or received by program traders on date $t$. Closing prices on are based on the closing mid-point of bid and ask prices. T-statistics are based on Newey-West standard errors with five lags.

Panel A: Calendar Time Portfolio Returns (Buys minus Sells)

CRSP

(1)

( 2 )

(3)

S\&P500

\begin{tabular}{|c|c|c|c|c|c|c|}
\hline & (1) & ( 2 ) & ( 3 ) & (4) & ( 5 ) & (6) \\
\hline $\begin{array}{c}\text { Constant (bp) } \\
(t-s t a t)\end{array}$ & $\begin{array}{l}-3.240 \\
(-17.05)\end{array}$ & $\begin{array}{l}-3.242 \\
(-17.09)\end{array}$ & $\begin{array}{l}-3.315 \\
(-16.92)\end{array}$ & $\begin{array}{l}-2.955 \\
(-15.40)\end{array}$ & $\begin{array}{l}-2.956 \\
(-15.40)\end{array}$ & $\begin{array}{l}-3.029 \\
(-15.30)\end{array}$ \\
\hline$\underset{\text { (t-stat) }}{\mathrm{Rm}-\mathrm{Rf}(\times 100)}$ & & $\begin{array}{l}0.200 \\
(0.79)\end{array}$ & $\begin{array}{l}0.140 \\
(0.46)\end{array}$ & & $\begin{array}{l}0.145 \\
(0.55)\end{array}$ & $\begin{array}{l}0.140 \\
(0.43)\end{array}$ \\
\hline $\begin{array}{c}\text { SMB }(\times 100) \\
(t-\text { stat })\end{array}$ & & & $\begin{array}{l}1.143 \\
(2.31)\end{array}$ & & & $\begin{array}{l}1.023 \\
(2.12)\end{array}$ \\
\hline $\begin{array}{c}\text { HML }(\times 100) \\
(t-\text { stat })\end{array}$ & & & $\begin{array}{l}-0.615 \\
(1.34)\end{array}$ & & & $\begin{array}{l}-0.459 \\
(-0.98)\end{array}$ \\
\hline$\underset{(t-\text { stat })}{\operatorname{MOM}(\times 100)}$ & & & $\begin{array}{l}1.415 \\
(5.26)\end{array}$ & & & $\begin{array}{l}1.361 \\
(5.31)\end{array}$ \\
\hline
\end{tabular}

Panel B: Average Daily Trading Revenues (Buys minus Sells)

\begin{tabular}{ccc}
$\begin{array}{c}\text { Date Position } \\
\text { is Closed } \\
\text { (at Midquote) }\end{array}$ & $\begin{array}{c}\text { CRSP } \\
\text { (t-stat) }\end{array}$ & $\begin{array}{c}\text { S\&P500 } \\
\text { (t-stat) }\end{array}$ \\
\hline $\mathbf{t}$ & $-286,016$ & $-121,534$ \\
& $(-3.32)$ & $(-1.53)$ \\
$\mathbf{t}+\mathbf{1}$ & $-1,914,493$ & $-1,428,174$ \\
& $(-7.47)$ & $(-6.59)$ \\
$\mathbf{t}+\mathbf{2}$ & $-2,237,162$ & $-1,580,474$ \\
& $(-5.75)$ & $(-4.74)$
\end{tabular}


Table 7

Program Trading Around Index Additions

Panel A shows program trading activity for different time periods around eighty S\&P500 Index additions from year 2000 to 2004. For each event, turnover is program trading buy volume plus sell volume normalized by shares outstanding. Order imbalance $(O I B)$ is program trading shares bought minus shares sold normalized by shares outstanding. Panel B reports measures of $O I B$ comovement prior to the addition, days [-250,-51], and following the stock's addition, days $[+51,+250]$. Univariate measures come from regressions of each stock's OIB on the value-weighted OIB of other S\&P500 stocks. Bivariate measures come from regressions of each stock's OIB on the value-weighted OIB of other S\&P500 and the value-weighted OIB of other non-S\&P500 stocks. Panel C provides measures of cross comovement from regressions of each stock's returns on the OIB of the value weighted return of other stocks in the S\&P500 Index.

Panel A: Turnover and Cumulative OIB of Program Traders (Effective Dates)

\begin{tabular}{ccc} 
Time Window & Turnover & $\begin{array}{c}\text { Cumulative } \\
\text { OIB }\end{array}$ \\
\hline [-20,-6] & 15.96 & 9.99 \\
{$[-5,-1]$} & 19.44 & 10.33 \\
{$[\mathbf{0 , 0}]$} & 170.74 & 30.73 \\
{$[\mathbf{+ 1 , + 5 ]}$} & 31.92 & 30.89 \\
{$[\mathbf{+ 6 , + 2 0 ]}$} & 21.36 & 28.92 \\
{$[\mathbf{- 2 0 , + 2 0}]$} & 24.08 & 110.86
\end{tabular}

Panel B: Order Imbalance Comovement

\begin{tabular}{lcccc} 
& \multicolumn{2}{c}{ Univariate } & \multicolumn{2}{c}{ Bivariate } \\
& Fit $\left(\mathbf{R}^{2}\right)$ & $\beta_{\text {sp500 }}$ & $\beta_{\text {sp500 }}$ & $\beta_{\text {nonsp500 }}$ \\
\hline Pre Event & 0.011 & 0.268 & -0.073 & 1.014 \\
Post Event & 0.031 & 0.818 & 0.702 & 0.231 \\
$\Delta$ Post-Event & 0.020 & 0.550 & 0.775 & -0.783 \\
(T-Stat of Diff) & $(4.03)$ & $(3.86)$ & $(5.51)$ & $(-6.08)$
\end{tabular}

Panel C: Cross Comovement of Returns on Order Imbalance

\begin{tabular}{lcc} 
& Fit $\left(\mathbf{R}^{\mathbf{2}}\right)$ & $\boldsymbol{\beta}_{\text {sp500 }}$ \\
\hline Pre Event & 0.030 & 44.0 \\
Post Event & 0.073 & 70.1 \\
$\Delta$ Post-Event & 0.043 & 26.1 \\
(T-Stat of Diff) & $(4.55)$ & $(3.25)$
\end{tabular}




\section{Figure 1 \\ Market Order Imbalance}

The figure shows the aggregate program trading order imbalances for S\&P500 stocks over our sample period. Order imbalance for each stock is program trading shares bought minus shares sold normalized by shares outstanding. Values are aggregated across stocks using market capitalization weights. Units shown are in basis points of market capitalization.

Panel A: CRSP

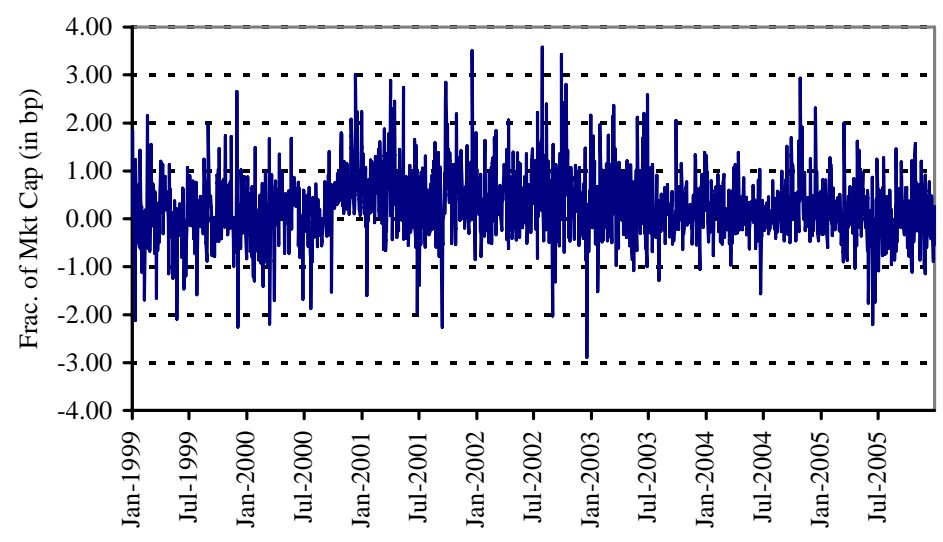

Panel B: S\&P500

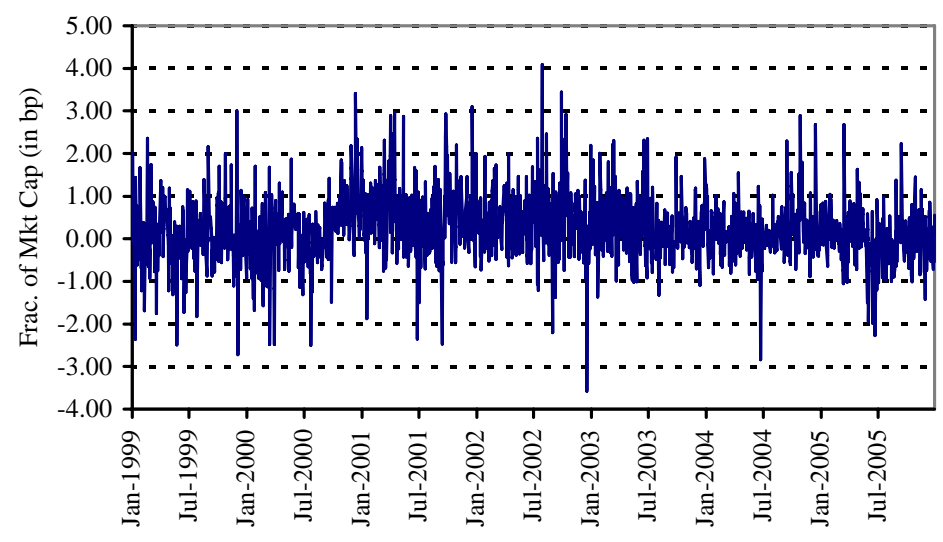




\section{Figure 2}

\section{Impulse Response Function of the Response of Returns to a Shock in Order Imbalance}

The figure shows the impulse response functions (IRFs) from a daily bivariate vector autogression (VAR) of market-level returns and order imbalances with 4 lags. Returns are value-weighted. Order imbalance (OIB) for each stock is program trading shares bought minus shares sold normalized by shares outstanding. OIB is aggregated across stocks using market capitalization weights. The 95\% confidence bounds are shown.

Panel A: CRSP
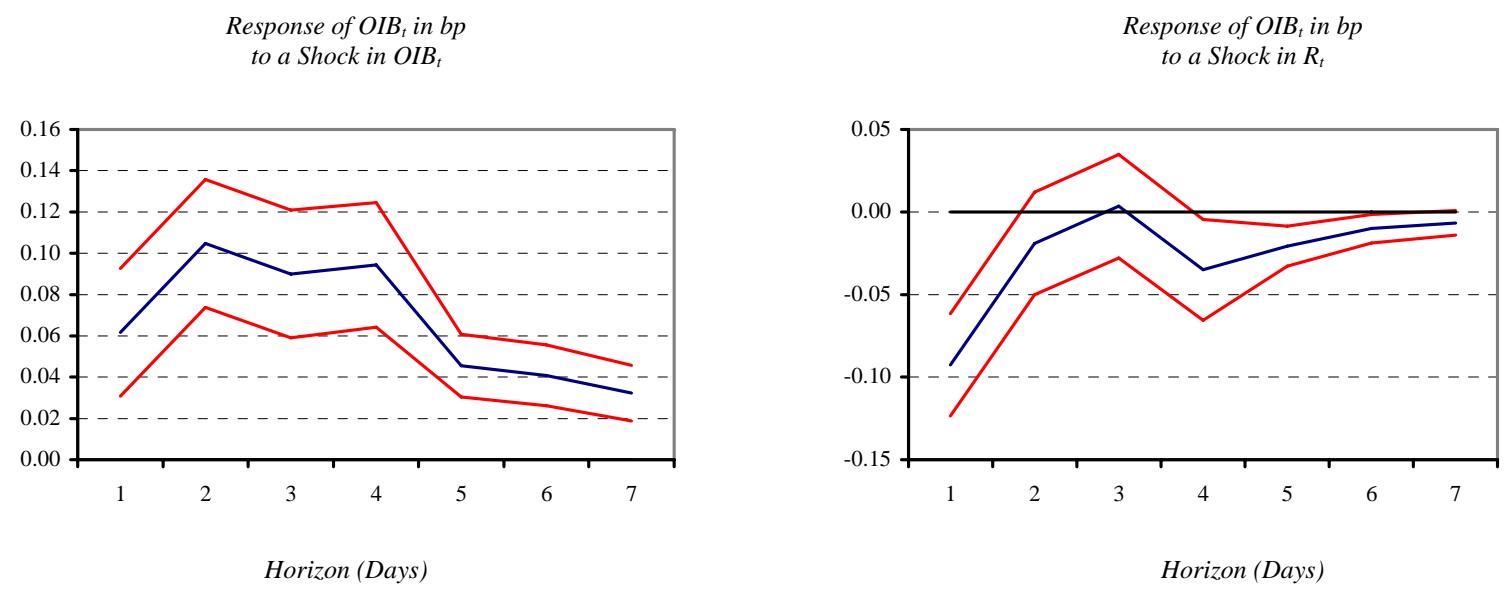

Response of $R_{t}$ in $b p$

Response of $R_{t}$ in $b p$ to a Shock in $\mathrm{OIB}_{t}$

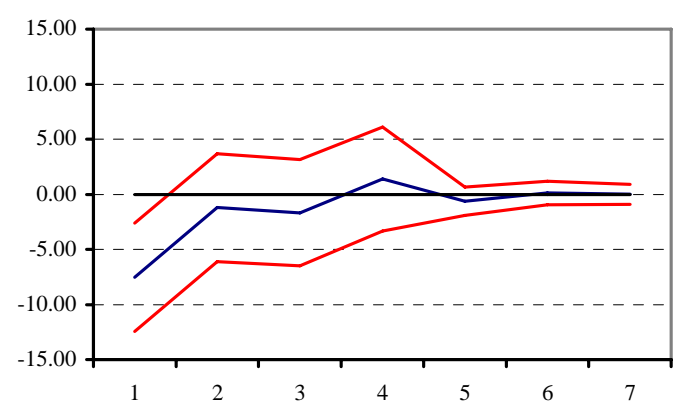

Horizon (Days)

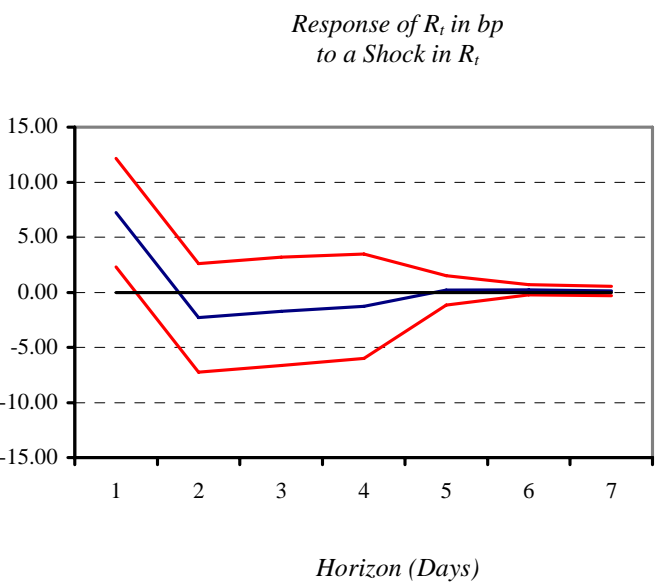


Figure 2

Continued

Panel B: S\&P500

Response of $\mathrm{OIB}_{\mathrm{sp} 500}$ in $\mathrm{bp}$ to a Shock in OIB $B_{s p 500}$

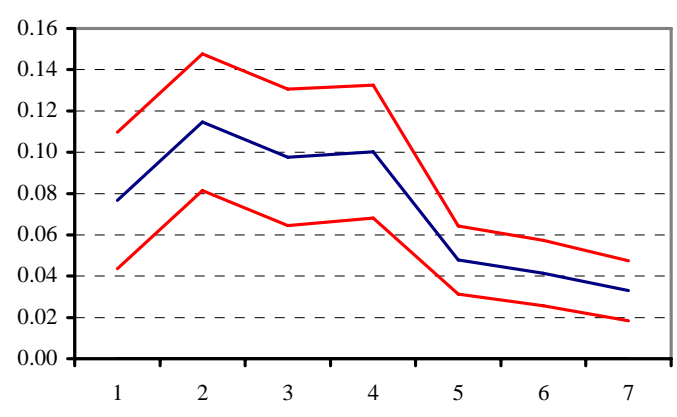

Horizon

Response of $R_{s p 500}$ in $b p$

to a Shock in $\mathrm{OIB}_{s p 500}$

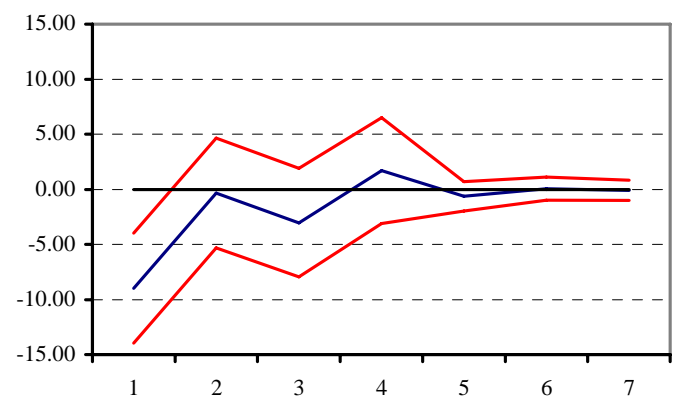

Horizon
Response of $\mathrm{OIB}_{\mathrm{sp} 500}$ in $b p$ to a Shock in $R_{s p 500}$

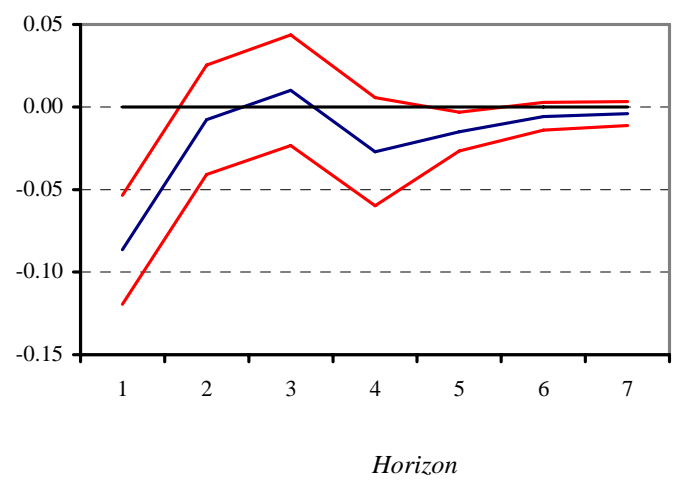

Response of $R_{s p 500}$ in $b p$ to a Shock in $R_{s p 500}$

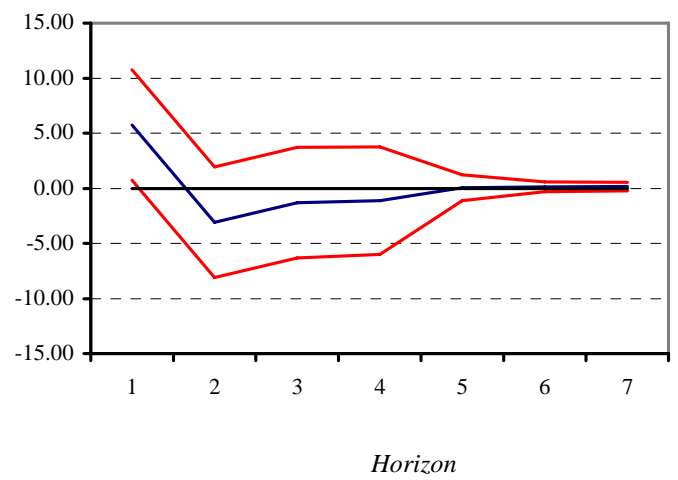


Figure 3

\section{Program Trading Around Index Additions}

The figures show program trading behavior around stocks' addition to the S\&P500 index. The left two diagrams use announcement date as day $\mathrm{t}=0$. The right two diagrams use the effective date as day $\mathrm{t}=0$. The top two diagrams show turnover defined as shares bought plus shares normalized by shares outstanding.. The bottom two diagrams show program traders' cumulative order imbalances defined as shares bought minus shares sold normalized by shares outstanding in basis points.

Program Traders Turnover Around Announcement Dates

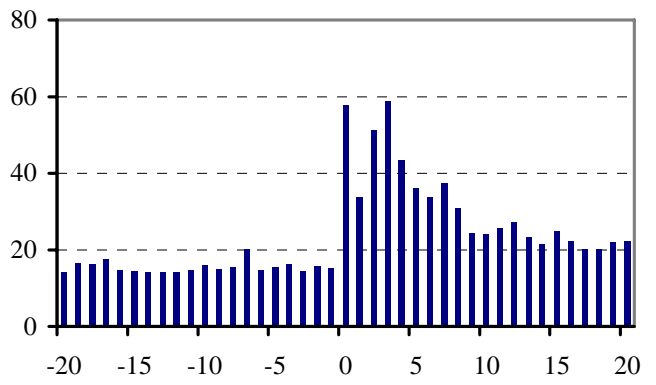

Days Relative

Program Traders

Cumulative OIB (Buys - Sells)

Around Announcement Dates

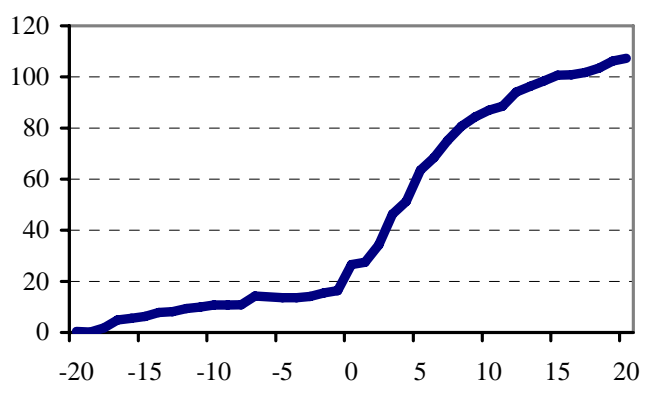

Days Relative
Program Traders

Turnover Around Effective Dates

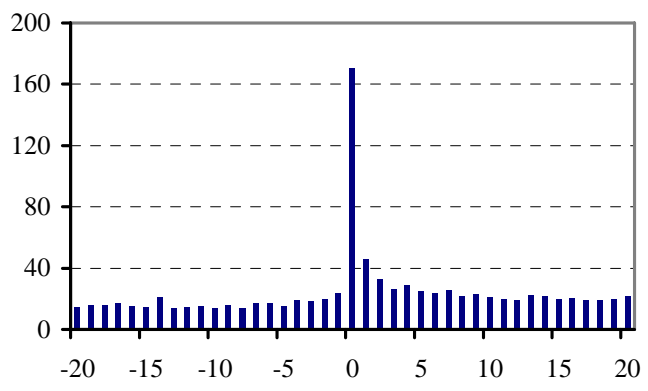

Days Relative

Program Traders

Cumulative OIB (Buys - Sells)

Around Effective Dates

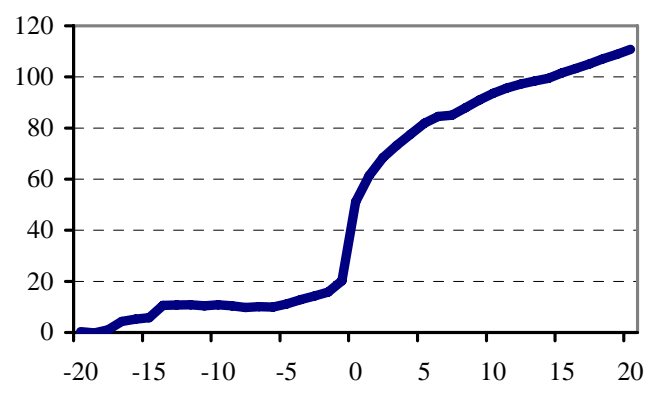

Days Relative 